\title{
Condicionadores alternativos de substrato na qualidade da muda e produtividade de couve manteiga
}

\author{
Alternative substrate conditioners in seedling quality and yield of kale \\ Nilciléia Mendes da Silva ${ }^{I^{*}}$, Antônio Carlos Simões², Gisley Karoline Emerick Bitancourt Alves ${ }^{3}$, Regina Lúcia Félix \\ Ferreira $^{4}$, Sebastião Elviro de Araújo Neto ${ }^{5}$
}

\begin{abstract}
Resumo: Objetivou-se avaliar o efeito de condicionadores de substrato na qualidade da muda e produtividade de couve manteiga cv. Geórgia. O delineamento experimental foi em blocos casualizados com seis tratamentos e quatro repetições. Os tratamentos constaram de substratos orgânicos contendo os seguintes condicionadores: Casca de arroz carbonizada; Fibra casca de coco; Composto orgânico puro; Estipe de palmeira ouricurí picado; Caule decomposto de sumaúma e Substrato comercial, que foi utilizado como tratamento controle. Foi instalado um experimento em viveiro e outro em campo, ambos em delineamento de blocos ao acaso com quatro repetições, sendo a unidade experimental de 10 mudas no viveiro e 08 plantas em campo, foi realizado no período de março a julho de 2013 no Sítio Ecológico Seridó em Rio Branco, AC. Avaliou-se aos 30 dias após a semeadura o índice de qualidade de muda, a massa seca da parte aérea e raiz das mudas de couve, e no experimento à campo, aos 70 dias após o transplantio avaliou-se a massa seca da parte aérea, massa fresca comercial, produtividade, massa média de folha fresca e número de folha por planta. Substratos contendo composto orgânico puro ou condicionadores de casca de arroz carbonizada, fibra de coco ou estipe de palmeira produzem mudas com qualidade superior. Porém, a inferioridade das mudas produzidas com substrato de caule decomposto de sumaúma não diminui a produtividade da couve.
\end{abstract}

Palavras-chave: Brassica oleracea var. acephala. Horticultura orgânica. Qualidade da muda.

Abstract: Objective was to evaluate the effect of substrate conditioners in the quality of seedling and productivity of kale cv. Geórgia. The experimental design was randomized blocks with six treatments and four replications. Treatments consisted of the organic substrates: carbonized rice husk, coconut shell fiber, organic compost, chopped palm stipe, decomposed kapok stem and commercial substrate, used as control treatment. An experiment was carried out in a greenhouse and another in the field, the both following the randomized blocks design, with four replications, and the experimental unit of 10 seedlings in the greenhouse and eight plants in the field, from March to July 2013, in Sítio Ecológico Seridó in Rio Branco, Acre State, Brazil. Was evaluated at 30 days after sowing the seedling quality index, dry mass of shoots and roots of kale, and in experiment of field, 70 days after transplanting to the evaluated the dry mass of the aerial part, commercial fresh weight, yield, mass fresh leaf and number of leaves per plant. The substrate containing organic compost or conditioner of carbonized rice husk, coconut shell fiber or chopped palm stipe produced seedlings with the highest quality. However, the inferiority of seedlings produced with decomposed kapok stem substrate does not reduce productivity of kale.

Key words: Brassica oleracea var. acephala. Organic horticulture. Quality seedling.

\footnotetext{
*Autor para correspondência

Recebido para publicação em 20/01/2016; aprovado em 15/10/2016

${ }^{1}$ Engenheira Agrônoma Mestranda em Produção Vegetal, Universidade Federal do Acre, Rio Branco-AC, nilcileia-ac@ hotmail.com

${ }^{2}$ Engenheiro Agrônomo Mestre em Produção Vegetal, Universidade Federal do Acre, ttoni_23@hotmail.com

${ }^{3}$ Engenheira Agrônoma Mestre em Produção Vegetal, Universidade Federal do Acre, gisley_karoline@hotmail.com

${ }^{4}$ Engenheira Agrônoma Dra. em Agronomia (Fitotecnia), professora da Universidade Federal do Acre, reginalff@ yahoo.com.br

${ }^{5}$ Engenheiro Agrônomo Dr. em Agronomia (Fitotecnia), professor da Universidade Federal do Acre, selviro2000@ yahoo.com.br
} 


\section{INTRODUÇÃO}

Pertencente à família brassicaceae, que contempla o maior número de culturas oleráceas, a couve-de-folha (Brassica oleracea variedade acephala) é uma espécie bienal, não apresenta "cabeça", a emissão de novas folhas é constante formando uma roseta ao redor do caule e a sua propagação pode ser realizada por sementes ou rebentos laterais (FILGUEIRA, 2013). Em geral, uma planta de couve produz de três a quatro quilos de folhas e na sua composição encontram-se vitaminas: A, C, D, E, K e do complexo B e minerais: ferro, cálcio, enxofre, potássio e magnésio (VIDIGAL; PEDROSA, 2007).

$\mathrm{Na}$ implantação da cultura dacouve é comum a utilização dos rebentos laterais para cultivares que os emitem, mas para cultivares que emitem pouco ou nenhum rebento lateral os agricultores optam pela produção de mudas em bandejas a partir de sementes. De acordo com a instrução normativa $\mathrm{n}^{\circ} 46$ de 6 de outubro de 2011 (BRASIL, 2011), que regulamenta a produção orgânica, é obrigatório utilizar mudas orgânicas. Porém o volume e a qualidade do substrato, ausente de fertilizantes químicos de alta solubilidade e concentração pode reduzir a qualidade das mudas produzidas em recipiente, por afetar principalmente o sistema radicular (SOUZA; REZENDE, 2006).

Além da produção da muda, todo processo de produção orgânica surgiu da demanda por alimentos orgânicos que vem aumentando a cada dia em razão da conscientização alimentar e ambiental dos consumidores e agricultores. Estes alimentos são mais valorizados pela sua superioridade na qualidade, por apresentar maior concentração de fibras, matéria seca e quantidade de nutrientes comparado aos alimentos produzidos de forma convencional. Além disso, utilizam-se práticas agrícolas conservacionistas como uso de composto, biofertilizantes, adubação verde, plantio direto, cultivos consorciados, variedades adaptadas e defensivos alternativos (SILVA et al., 2011; SOUZA; RESENDE 2006)

Assim, a agricultura orgânica necessita de práticas alternativas para aumento da produção de alimentos de forma sustentável, um exemplo que pode ser destacado é a substituição de substratos comerciais por alternativos disponíveis na região. O substrato é um dos elementos responsáveis pela qualidade da muda de hortaliças e tem como finalidade fornecer nutrientes para a muda em formação, bem como servir de base para a plântula até seu transplantio, sendo sua escolha feita em função de suas características físico-químicas, da espécie ou cultivar a ser propagada e do custo e disponibilidade de aquisição (ARAÚJO NETO, 2011). Todavia, no Acre há carência de substrato comercial e um dos motivos principais é a distância dos centros produtores. Por isso, é de suma importância incrementar condicionadores de substrato disponíveis na região como resíduos do caule de palmeira, composto orgânico, madeira decomposta, dentre outros resíduos (SIMÕES et al., 2015).

Os condicionadores de substratos são substâncias que conferem características adequadas aos substratos, principalmente, as características físico-hídricas (FERRAZ et al., 2005). Dentre os condicionadores com potencial de uso em substratos destacam-se a casca de arroz carbonizada, fibra de casca de coco, composto orgânico, fibra de estipe de palmeiras e resíduos de madeira (CARDOSO et al., 2011; PEREIRA et al., 2012; FREITAS et al., 2013a; FERRAZ et al., 2014; SIMÕES et al., 2015).

Apesar da qualidade da muda ser largamente relatado e por afetar a produtividade das culturas no campo, poucos estudos avaliam o efeito da qualidade da muda na fase de campo, principalmente em espécies de ciclo curto e médio, como a couve manteiga. Portanto, objetivou-se avaliar o efeito de condicionadores de substrato na qualidade da muda e produtividade de couve manteiga cv. Geórgia.

\section{MATERIAL E MÉTODOS}

A avaliação dos substratos (condicionadores) foi realizada em duas fases: produção de mudas em viveiro e cultivo à campo.

O experimento foi realizado no Sítio Ecológico Seridó, localizado na Rodovia AC-10, km 04, em Rio Branco (AC), situado a latitude $09^{\circ} 53^{\prime} 10,6^{\prime}$ ' S e longitude $67^{\circ} 49^{\prime}$ 08, 6" W, com altitude média de $170 \mathrm{~m}$, no período de março a julho de 2013. O clima, segundo a classificação de Köppen, é do tipo Am, sendo, portanto, um clima equatorial com variação para o tropical quente e úmido, com estação seca bem definida, junho a setembro, temperaturas médias anuais variando em torno $24,5^{\circ} \mathrm{C}$, umidade relativa do ar de $84 \%$ e a precipitação anual varia de 1.700 a $2.400 \mathrm{~mm}$.

O solo da área experimental é classificado como ARGISSOLO AMARELO Alítico plintossólico (SANTOS et al., 2013). Durante cinco anos de cultivo orgânico, o solo apresentava a seguinte composição química na camada de 0 $20 \mathrm{~cm}: \mathrm{pH}=5,6 ;$ M.O. $=51,3$ g.dm ${ }^{-3} ; \mathrm{P}=256,5 \mathrm{mg} \cdot \mathrm{dm}^{-3} ; \mathrm{K}=$ $8,1 \mathrm{mmol}_{\mathrm{c}} \cdot \mathrm{dm}^{-3} ; \mathrm{Ca}=87,5 \mathrm{mmol}_{\mathrm{c}} \cdot \mathrm{dm}^{-3} ; \mathrm{Mg}=58 \mathrm{mmol}_{\mathrm{c}} \cdot \mathrm{dm}^{-3}$; $\mathrm{Al}=0,00 \mathrm{mmol}_{\mathrm{c}} \cdot \mathrm{dm}^{-3} ; \mathrm{H}+\mathrm{Al}=28,5 \mathrm{mmol}_{\mathrm{c}} \cdot \mathrm{dm}^{-3} ; \mathrm{SB}=153,6$ $\mathrm{mmol}_{\mathrm{c}} \cdot \mathrm{dm}^{-3} ; \mathrm{CTC}=182,1 \mathrm{mmol}_{\mathrm{c}} \cdot \mathrm{dm}^{-3} ; \mathrm{V}=84,35 \% ; \mathrm{Ca} / \mathrm{Mg}=$ 1,52 e $\mathrm{Mg} / \mathrm{K}=8,13$.

O delineamento experimental foi em blocos casualizados com seis tratamentos (substratos) e quatro repetições. Para a avaliação da qualidade da muda foram utilizadas dez plantas por repetição e para a fase de campo, as parcelas medindo 2,0 $\mathrm{m}$ de comprimento por 3,6 $\mathrm{m}$ de largura, foram compostas por 16 plantas de couve manteiga cv. Geórgia plantadas no espaçamento de $0,90 \mathrm{~m} \times 0,50 \mathrm{~m}$.

Os tratamentos foram constituídos por alteração do condicionador, sendo: $\mathrm{T}_{1}=$ casca de arroz carbonizada; $\mathrm{T}_{2}=$ fibra da casca de coco (Cocos nucifera); $\mathrm{T}_{3}=$ composto orgânico; $\mathrm{T}_{4}=$ fibra do caule da palmeira ouricurí (Attalea phalerata) triturado; $\mathrm{T}_{5}=$ caule decomposto de sumaúma (Ceiba pentandra (L.) Gaertn) e $\mathrm{T}_{6}=$ substrato comercial. $\mathrm{O}$ substrato $\mathrm{T} 3$ foi considerado um tratamento controle por ser constituído de $100 \%$ de composto, os demais apresentaram a seguinte proporção: terra (30\%), composto orgânico (30\%) e condicionador $(30 \%)$ mais adição de fino de carvão (10\%), 1,0 kg.m-3 de calcário dolomítico, 1,5 kg.m-3 de termofosfato natural e 1,0 kg.m-3 de sulfato de potássio.

Os componentes orgânicos dos substratos foram triturados e posteriormente peneirados para melhor homogeneização.

As análises químicas (Tabela 1) e físicas (Tabela 2) dos substratos foram feitas no Instituto Campineiro de Análise de Solo e Água - ICASA. 
Tabela 1. Composição química dos substratos com diferentes condicionadores

\begin{tabular}{|c|c|c|c|c|c|c|c|c|c|c|c|}
\hline Substratos & $\mathrm{pH}$ & $\mathrm{P}$ & $\mathrm{K}$ & $\mathrm{Ca}$ & $\mathrm{Mg}$ & $\mathrm{S}$ & B & $\mathrm{Cu}$ & $\mathrm{Fe}$ & $\mathrm{Mn}$ & $\mathrm{Na}$ \\
\hline Casca de arroz & 7,5 & 5,9 & 184,0 & 108,0 & 408,0 & 36,3 & 0,21 & 0,02 & 3,76 & 0,12 & 10,0 \\
\hline Fibra de coco & 7,4 & 5,0 & 166,0 & 59,1 & 22,5 & 27,4 & 0,17 & 0,02 & 4,76 & 0,18 & 14,0 \\
\hline Composto orgânico & 6,2 & 30,2 & 69,0 & 221,0 & 80,2 & 46,3 & 0,18 & 0,10 & 4,82 & 5,47 & 8,4 \\
\hline Substrato comercial & 5,3 & 0,4 & 84,0 & 128,0 & 70,1 & 183,0 & 0,87 & 0,01 & 0,36 & 0,11 & 14,4 \\
\hline Caule de palmeira & 6,5 & 20,2 & 348,0 & 153,0 & 88,0 & 87,1 & 0,28 & 0,03 & 1,99 & 0,82 & 12,0 \\
\hline Resíduo sumaúma & 8,1 & 2,3 & 140,0 & 130,0 & 410,0 & 35,2 & 0,10 & 0,03 & 3,61 & 0,15 & 9,4 \\
\hline
\end{tabular}

Casca de Arroz Carbonizada + mistura (10\% v/v de pó de carvão vegetal, $1,0 \mathrm{~kg} \mathrm{~m}^{-3}$ de calcário dolomítico e $1,5 \mathrm{~kg} \mathrm{~m}^{-3}$ de termofosfato natural); Casca de Coco + mistura; Composto orgânico; Golden ${ }^{\circledR}$; Caule de palmeira + mistura; Sumaúma + mistura

Tabela 2. Características físicas dos substratos com diferentes condicionadores

\begin{tabular}{|c|c|c|c|c|c|c|c|c|}
\hline Substratos & DA & $\begin{array}{c}\mathrm{DP} \\
-3\end{array}$ & EP & $\begin{array}{l}\text { PS } \\
\%-\end{array}$ & C.R.A. & $\begin{array}{c}\text { C.T.C } \\
\mathrm{mMol}_{\mathrm{c}} \cdot \mathrm{kg}^{-1}\end{array}$ & $\begin{array}{c}\text { C.E } \\
\text { mili.Scm }\end{array}$ & $\begin{array}{c}\text { M.O } \\
\text { g. } 100 \mathrm{~g}^{-1}\end{array}$ \\
\hline Casca de arroz & 720,6 & 2423,1 & 75,6 & 24,4 & 90,70 & 102,5 & 0,430 & 13,19 \\
\hline Fibra de coco & 589,9 & 2298,6 & 78,9 & 21,1 & 91,72 & 95,0 & 0,359 & 21,54 \\
\hline Composto orgânico & 649,5 & 2314,8 & 83,9 & 16,1 & 151,42 & 135,0 & 0,494 & 20,41 \\
\hline Substrato comercial & 454,0 & 1989,1 & 88,2 & 11,8 & 219,34 & 347,5 & 0,410 & 46,82 \\
\hline Caule de palmeira & 779,3 & 2373,7 & 75,9 & 24,1 & 102,30 & 107,5 & 0,854 & 16,40 \\
\hline Resíduo de sumaúma & 742,0 & 2380,3 & 76,9 & 23,1 & 106,60 & 160,0 & 0,489 & 15,90 \\
\hline
\end{tabular}

DA = densidade aparente (base seca); DP = densidade das partículas; $\mathrm{EP}=$ espaço poroso; PS = partículas sólidas; C.T.C = capacidade de troca de cátions; C.R.A = Capacidade de retenção de água; C.E = condutividade elétrica. $\mathrm{M} . \mathrm{O}=$ Matéria orgânica.

A formação das mudas foi realizada em bandejas de poliestireno de 128 células, sendo utilizada a couve manteiga cv. Geórgia. Na semeadura foram utilizadas 3 sementes por célula e oito dias após realizado desbaste, deixando uma plântula por célula, que foram transplantadas para o campo aos 30 dias após a semeadura.

O preparo do solo constou de aração com arado de aiveca e gradagem com grade cultivadora de cinco facas e seis discos, ambos de tração animal. A adubação constou de 15 t.ha $^{-1}$ de composto orgânico (base seca) incorporado no momento de construção dos camaleões com enxada manual a $20 \mathrm{~cm}$ de altura.

A irrigação foi do tipo micro aspersão, sendo aplicado uma lâmina média de $6 \mathrm{~mm} \cdot \mathrm{dia}^{-1}$, elevando-se o teor de água no solo próximo à capacidade de campo, durante todo o ciclo da cultura. O controle de pragas foi realizado com aplicações preventivas de óleo de nim a $1 \%$ a cada quinze dias e de doenças com inseticida microbiano à base de Bacillus thuringiensis, especificamente para lagartas da couve. Foram realizadas cinco capinas para o controle de plantas espontâneas aos 10, 20, 30 e 40 dias após o transplantio. As colheitas foram semanais e iniciadas 20 dias após o transplantio com duração até os 70 dias.

Foram avaliadas aos 30 dias após a semeadura, na fase de muda, as seguintes características: massa seca da parte aérea (MSPA), massa seca de raiz (MSR) e índice de qualidade do desenvolvimento da muda (IQD). No plantio à campo, foram avaliados massa fresca comercial (MFC), massa seca da parte aérea comercial (MSPAC), produtividade comercial (PRODC), massa média de folha fresca (MMFF) e número de folhas por planta (NFP).

Para a determinação do índice de qualidade do desenvolvimento (IQD) foi aplicada a metodologia de Dickson et al. (1960) determinado através das seguintes variáveis: massa seca da parte aérea e das raízes, massa seca total, altura e diâmetro do colo das mudas, conforme a equação 1 .

$$
I Q D=\frac{\mathrm{MST}}{\left(\frac{\mathrm{H}}{\mathrm{DC}}\right)+\left(\frac{M S P A}{M S R}\right)}
$$

Sendo: IQD = Índice de qualidade de Dickson; MST = Massa seca total $(\mathrm{g}) ; \mathrm{H}=$ Altura $(\mathrm{cm}) ; \mathrm{DC}=$ Diâmetro do colo $(\mathrm{mm})$; MSPA = Massa seca da parte aérea $(\mathrm{g}) ; \mathrm{MSR}=$ Massa seca da raiz $(\mathrm{g})$.

Para a avaliação das variáveis na fase de muda as raízes foram lavadas em água corrente para retirada do substrato aderido e separando o sistema radicular da parte aérea. Para obtenção da massa seca da parte aérea e das raízes, as plantas foram acondicionadas em sacos de papel kraft, identificados e encaminhadas para estufas com circulação forçada de ar a $65{ }^{\circ} \mathrm{C}$, aferindo-se a massa diariamente e retirou-se da estufa após 72 horas quando as amostras apresentaram massa seca constante e depois aferiuse a massa em balança analítica de precisão.

A massa fresca comercial foi obtida considerando a massa das plantas obtida após a retirada de folhas sujas, senescentes ou doentes.

Para estimativa da produtividade comercial foi multiplicado a massa fresca comercial das plantas para cada metro quadrado de área cultivada $\left(\mathrm{g} \mathrm{m}^{-2}\right)$.

Para a análise estatística iniciou-se com a verificação da presença de outliers com teste de Grubbs, da normalidade dos erros pelo teste de Shapiro e Wilk e da homogeneidade das variâncias pelo teste de Bartlett. Após verificar os pressupostos da experimentação, efetuou-se análise de variância pelo teste $\mathrm{F}$ e comparação das médias dos tratamentos pelo teste de Tukey, ao nível de probabilidade de $5 \%(\mathrm{p}<0,05)$

\section{RESULTADOS E DISCUSSÃO}

Observou-se efeito dos condicionadores na massa seca da raiz e parte aérea da muda e consequentemente na sua qualidade (IQD) que influenciou na massa fresca de folhas por planta e na produtividade, mesmo não afetando a massa média da folha fresca, a massa seca das folhas comerciais e o número de folha por planta (Tabelas 3 e 4). 
A massa seca da raiz de mudas produzidas com substratos contendo os condicionadores caule de palmeira e o substrato com $100 \%$ de composto orgânico foi superior, mas não diferiu estatisticamente daqueles substratos contendo casca de arroz, fibras de coco e resíduo de sumaúma e estes substratos proporcionaram de 11,1 a $33,3 \%$ mais massa da raiz que o substrato comercial, utilizado como testemunha (Tabela 3). Estes condicionadores apresentam menor capacidade de retenção de água (Tabela 2), o que contribuiu para maior expansão do sistema radicular, pois quando há déficit hídrico as raízes expandem em busca de zonas úmidas e profundas (SANTOS; CARLESSO, 1998).

A massa seca da parte aérea foi superior em mudas produzidas com substrato de composto orgânico (Tabela 3). Este maior acúmulo de massa seca condiz com a quantidade e o equilíbrio dos nutrientes, principalmente fósforo (Tabela 1), e possui alta concentração de matéria orgânica, contribuindo com o aumento de micro-organismos; melhoria na porosidade, retenção e infiltração de água e maior capacidade de troca de cátions (MINAMI, 2010; CARDOSO et al., 2011).

Tabela 3. Massa seca da parte aérea (MSPA), massa seca de raiz (MSR), índice de qualidade de mudas (IQD) de couve manteiga cv. Geórgia, 30 dias após a semeadura, em função da utilização de diferentes substratos

\begin{tabular}{lccc}
\hline Condicionadores & MSR & MSPA & IQD \\
\hline Casca de arroz & $-------------\left(\right.$ g.planta $\left.{ }^{-1}\right)----------$ & $0,031 \mathrm{bc}$ & $0,00348 \mathrm{ab}$ \\
Fibra de coco & $0,0115 \mathrm{ab}$ & $0,034 \mathrm{bc}$ & $0,00413 \mathrm{ab}$ \\
Composto orgânico & $0,0113 \mathrm{ab}$ & $0,052 \mathrm{a}$ & $0,00443 \mathrm{a}$ \\
Substrato comercial & $0,0120 \mathrm{a}$ & $0,018 \mathrm{~d}$ & $0,00308 \mathrm{~b}$ \\
Caule de palmeira & $0,0090 \mathrm{~b}$ & $0,035 \mathrm{~b}$ & $0,00375 \mathrm{ab}$ \\
Resíduo de sumaúma & $0,0120 \mathrm{a}$ & $0,022 \mathrm{~cd}$ & $0,00305 \mathrm{~b}$ \\
\hline CV\% & $0,0100 \mathrm{ab}$ & 17,4 & 14,7 \\
\hline
\end{tabular}

Médias seguidas de mesma letra na coluna, não diferem estatisticamente entre si, pelo teste de Tukey a 5\% de probabilidade $(\mathrm{p}<0,05)$.

O composto orgânico promoveu maior índice de qualidade do desenvolvimento da muda (IQD), porém, não diferiu estatisticamente do caule de palmeira ouricurí (Attalea phalerata), fibra de coco e casca de arroz carbonizada (Tabela 3). O IQD também pode ser utilizado para aferir se houve ou não estiolamento da muda, pois utiliza as variáveis diâmetro do colo e altura da planta e esta relação (altura/diâmetro) indica o equilíbrio no desenvolvimento da muda (CRUZ et al., 2006), com isso, quanto maior este índice melhor o padrão de qualidade das mesmas (DICKSON et al., 1960).

A produtividade e a massa fresca comercial da couve cultivado a partir de mudas formadas com substratos contendo composto orgânico, casca de arroz carbonizada, caule de ouricurí, caule decomposto de sumaúma ou fibra de coco foram superiores as plantas oriundas do substrato comercial (Tabela 4).

A boa formação de mudas é resultado da eficiência destes condicionadores que compõem o substrato. Apesar do caule decomposto de sumaúma não proporcionar bom desenvolvimento inicial na muda o seu desenvolvimento em campo não afetou a produtividade, que além da capacidade biológica da planta recuperar seu desenvolvimento (LARCHER, 2004) o equilíbrio planta-solo-ambiente também pode ter influenciado, já que na área experimental foi realizado cultivo orgânico há seis anos que de acordo com Oliveira et al. (2010) as hortaliças folhosas respondem bem adubação orgânica.

Apesar das características físico-hídricas estarem dentro dos padrões (Tabela 2), o substrato comercial produziu mudas de menor qualidade que contribuiu com a redução de $26 \%$ a $45 \%$ na produtividade (Tabela 3 e 4), essa resposta pode está relacionada a baixa concentração de ferro, fósforo e manganês (Tabela 1).

O fósforo é considerado nutriente-chave na produção em solos brasileiros, que influencia no desenvolvimento adequado do sistema radicular, na formação de mudas vigorosas, formação de matéria seca e elevação na produtividade. Por outro lado, os micronutrientes ferro e manganês, apesar do sistema radicular extrair pequenas quantidades, a sua ausência pode ser um fator limitante na produção da cultura (FILGUEIRA, 2013).

A casca de arroz carbonizada pode ser utilizada como condicionador de substrato por ser firme, porosa, leve, durável, estéril de nematoides, patógenos e plantas daninhas, além de não reagir com os nutrientes disponíveis no solo (FREITAS et al., 2013a; KRATZ et al., 2013). Sendo recomendado o uso de até $40 \%$ para a cultura da beterraba (WATTHIER et al., 2016) e segundo Freitas et al. (2013b) a adição de proporção crescente $(25,50,75,100 \%)$ promove redução nas características morfofisiológicas das mudas de alface.

A fibra da casca de coco se apresenta como ótima alternativa para aproveitamento no cultivo de hortaliças, por manter suas características físicas, reter água, apresentar boa drenagem e ser de baixo custo (COSTA et al., 2007; BARRETO et al., 2011). Apesar de poder surgir efeitos prejudiciais em espécies sensíveis à salinidade devido altos teores de sódio e cloro presentes no mesocarpo (JASMIM et al., 2006).

Embora não encontre na literatura uso do caule de palmeira e caule decomposto de sumaúma, os agricultores os utilizam como condicionadores (BOLDT, 2014; ARAÚJO NETO et al., 2015; SIMÕES et al., 2015), principalmente por ser abundante na região Amazônica (SOUZA et al., 2005; SALIS et al., 2007).

Apesar do número de folhas por planta e a massa fresca média da folha, não diferir significativamente entre os tratamentos (Tabela 4), a massa fresca por planta que é o resultado da multiplicação do número de folhas pela massa fresca da planta, diferiu significativamente, proporcionando ganhos de produtividade (Tabela 4), Reghin et al. (2007) afirmam que essas duas variáveis são importantíssimas na comercialização de hortaliças folhosas, pois são responsáveis pelo peso e volume da parte aérea. 
Tabela 4. Massa fresca comercial (MFC), massa seca da parte aérea (MSPA), produtividade comercial (PRODC), Massa Média de Folha Fresca (MMFF) e número de folha por planta (NFP) de couve manteiga cv. Geórgia, durante 70 dias após o transplantio, em função da utilização de diferentes substratos

\begin{tabular}{|c|c|c|c|c|c|}
\hline Condicionadores & \multicolumn{2}{|c|}{$\begin{array}{l}\text { MFC } \\
---\left(\text { g planta }^{-1}\right)-\ldots \\
\end{array}$} & \multirow{2}{*}{$\begin{array}{r}\begin{array}{r}\text { PRODC } \\
\left(\mathrm{g} \cdot \mathrm{m}^{-2}\right)\end{array} \\
1459,2 \mathrm{a}\end{array}$} & \multirow{2}{*}{$\begin{array}{c}\left.\begin{array}{c}\text { MMFF } \\
(\text { g.folha }\end{array}{ }^{-1}\right) \\
18,25 \mathrm{a}\end{array}$} & \multirow{2}{*}{$\begin{array}{r}\text { NFP } \\
30,6 \mathrm{a}\end{array}$} \\
\hline Casca de arroz & $656,7 \mathrm{a}$ & 77,6 a & & & \\
\hline Fibra de coco & $486,9 \mathrm{ab}$ & $75,4 \mathrm{a}$ & $1082,0 \mathrm{ab}$ & $18,80 \mathrm{a}$ & $24,6 \mathrm{a}$ \\
\hline Composto orgânico & $555,8 \mathrm{a}$ & $79,0 \mathrm{a}$ & $1235,2 \mathrm{a}$ & $21,18 \mathrm{a}$ & $24,8 \mathrm{a}$ \\
\hline Substrato comercial & $362,5 \mathrm{~b}$ & $64,0 \mathrm{a}$ & $805,6 \mathrm{~b}$ & $19,90 \mathrm{a}$ & $19,9 \mathrm{a}$ \\
\hline Caule de palmeira & $563,7 \mathrm{a}$ & $76,9 \mathrm{a}$ & $1252,6 \mathrm{a}$ & $19,13 \mathrm{a}$ & $25,5 \mathrm{a}$ \\
\hline Resíduo sumaúma & $544,5 \mathrm{a}$ & $85,2 \mathrm{a}$ & $1297,8 \mathrm{a}$ & $17,88 \mathrm{a}$ & $29,0 \mathrm{a}$ \\
\hline $\mathrm{CV} \%$ & 14,3 & 15,5 & 15,7 & 7,58 & 22,8 \\
\hline
\end{tabular}

Médias seguidas de mesma letra na coluna, não diferem estatisticamente entre si, pelo teste de Tukey a 5\% de probabilidade (p < 0,05).

\section{CONCLUSÃO}

Os substratos contendo composto orgânico puro ou condicionadores de casca de arroz carbonizada, fibra de coco ou estipe de palmeira ouricurí produzem mudas orgânicas de couve com qualidade superior. A produtividade no campo, não foi afetada pela qualidade inferior das mudas produzidas com substrato de caule decomposto de sumaúma, tornando estes condicionadores substitutos na composição de substratos para produção de mudas de couve manteiga cv. Geórgia. Porém, a baixa qualidade das mudas provenientes do substrato comercial reduziu a produtividade das plantas no campo.

\section{REFERÊNCIAS}

ARAÚJO NETO, S. E. de; FREDNBERG, N. T. N.; MINOSSO, S. C. C.; NOVELLI, D. da S.; ANDRADE NETO, R. de C. Condicionadores de substrato para produção orgânica de mudas de cupuaçu. Revista Brasileira de Fruticultura, Jaboticabal, v. 37, n. 4, p. 1083-1088, dez. 2015.

ARAÚJO NETO, S. E. de. Fruticultura tropical. Rio Branco, AC: UFAC, Centro de Ciências Biológicas e da Natureza, 2011. $232 \mathrm{p}$.

BARRETO, C. V. G.; TESTEZLAF, R.; SALVADOR, C. A. Ascensão capilar de água em substratos de coco e de pinus. Bragantia, v. 71, n. 3, p. 385-393, 2011.

BOLDT, R. H. Formação de mudas e produção de rúcula em função dos substratos. 2014. Dissertação (Mestrado em Agronomia) - Centro de Ciências Biológicas e da Natureza, Universidade Federal do Acre, Rio Branco, 2014.

BRASIL. Ministério da Agricultura. Instrução Normativa ${ }^{\circ}$ 46 de 06 de outubro de 2011. Disponível em: <www.agricultura.gov.br>. Acesso em: 24 maio 2017.

CARDOSO, A. I. I.; FERREIRA, K. P.; VIEIRA JÚNIOR, R. M.; ALCARDE, C. Alterações em propriedades do solo adubado com composto orgânico e efeito na qualidade das sementes de alface. Horticultura Brasileira, v. 29, n. 4, p. 594 599, out./dez. 2011.

COSTA C. A.; RAMOS S. J.; SAMPAIO R. A.; GUILHERME D. O.; FERNANDES L. A. Fibra de coco e resíduo de algodão para substrato de mudas de tomateiro. Horticultura Brasileira, v. 25 , n. 3 , p. 387-391, jul./set. 2007.
CRUZ, C. A. F.; PAIVA, H. N.; GUERRERO, C. R. A. Efeito da adubação nitrogenada na produção de mudas de sete-cascas (Samanea inopinata (Harms) Ducke). Revista Árvore, v. 30, n. 4, p. 537-546, 2006.

DICKSON, A.; LEAF, A. L.; HOSNER, J. F. Quality appraisal of white spruce and white pine seedling stock in nurseries. Forestry Chronicle, v. 36, n. 1, p. 10-13. 1960.

FERRAZ, M. V.; CANTURION, J, F.; BEUTLER, A. N. Caracterização física e química de alguns substratos comerciais. Acta Scientiarum Agronomy, v. 27, n. 2, p. 209214, Apr./Jun. 2005.

FERRAZ, P. A.; MENDES, R.; ARAÚJO NETO, S. E. de; FERREIRA, R. L. F. Produção de mudas orgânicas de bertalha em diferentes substratos. Enciclopédia Biosfera, Centro Científico Conhecer - Goiânia, v.10, n.18, p. 24412449. 2014.

FILGUEIRA, F. A. R. Novo manual de olericultura: agrotecnologia moderna na produção e comercialização de hortaliças. 3. ed. Viçosa, MG. 2013. 421 p.

FREITAS, G. A. de; BARROS, H. B.; SANTOS, M. M. dos; NASCIMENTO, I. R. do; COSTA, J. da L.; SILVA, R. R. da; Produção de mudas de alface sob diferentes substratos e proporções de casca de arroz carbonizada. Journal of Biotechnology and Biodiversity, v. 4, n. 3: p. 260-268, Aug. $2013 b$.

FREITAS, G. A.; SILVA, R. R.; BARROS, H. B.; VAZ-DEMELO, A.; ABRAHÃO, W. A. P. Produção de mudas de alface em função de diferentes combinações de substratos. Revista Ciência Agronômica, v. 44, n. 1, p. 159-166, jan./mar. 2013a.

JASMIM J. M.; TOLEDO R. R. V.; CARNEIRO L. A.; MANSUR E. Fibra de coco e adubação foliar no crescimento e na nutrição de Cryptanthus sinuosus. Horticultura Brasileira, v. 24, n. 3, p. 309-314, jul./set. 2006.

KRATZ, D.; WENDLING, I.; NOGUEIRA, A. C.; SOUZA, P. V. de. Propriedades físicas e químicas de substratos renováveis. Revista Árvore, v. 37, n. 6, p.1103-1113, 2013.

LARCHER, W. Ecofisiologia vegetal. Trad. PRADO, C. H. B. A. São Carlos: Rima, 2000, 2004. 531p. 
MINAMI, K. Produção de mudas de alta qualidade. Piracicaba: Degaspari. 440p. 2010.

OLIVEIRA, E. Q.; SOUZA, R. J.; CRUZ, M. C. M.; MARQUES, V. B.; FRANÇA, A. C. Produtividade de alface e rúcula, em sistema consorciado, sob adubação orgânica e mineral. Horticultura Brasileira, v. 28, n. 1, p. 36-40 jan./mar. 2010 .

PEREIRA, D. C.; GRUTZMACHER, P.; BERNARDI, F. H.; MALlMANN, L. S.; COSTA, L. A. M.; COSTA, M. S. S. M. Produção de mudas de almeirão e cultivo no campo, em sistema agroecológico. Revista Brasileira de Engenharia Agrícola e Ambiental, v. 16, n. 10, p. 1100-1106, 2012.

REGHIN, M. Y.; OTTO, R. F.; OLINIK, J. R.; JACOBY, C. F. S. Produtividade da chicória (Cichorium endivia L.) em função de tipos de bandejas e idade de transplante de mudas. Ciência e Agrotecnologia, v. 31, n. 3, p. 739-747, maio/jun. 2007.

SALIS, S. M.; CRISPIM, S. M. A.; BRANCO, O. D. Equação para estimar biomassa da Palmeira Acuri (Attalea phalearata) no Pantanal. Corumbá: Embrapa Pantanal, 2007. 4 p. (Comunicado Técnico, 63).

SANTOS, R. F.; CARLESSO, R. Déficit hídrico e os processos morfológico e fisiológico das plantas. Revista Brasileira de Engenharia Agrícola e Ambiental, v. 2, n. 3, p. 287-294, 1998.

SANTOS, H. G.; JACOMINE, P. K. T.; ANJOS, L. H. C.; OLIVEIRA, V. A.; LUMBRERAS, J. F.; COELHO, M. R.; ALMEIDA, J. A.; CUNHA, T. J. F.; OLIVEIRA, J. B. Sistema
Brasileiro de Classificação de Solos. 3. ed. Brasília, DF: Embrapa, 2013. 354 p.

SILVA, E. M. N. C. P.; FERREIRA, R. L. F.; ARAÚJO NETO, S. E.; TAVELLA, L. B.; SOLINO, A. J. S. Qualidade de alface crespa cultivada em sistema orgânico, convencional e hidropônico. Horticultura Brasileira, v. 29, n. 2, p. 242-245, abr./jun. 2011.

SOUZA, J. L.; RESENDE, P. L. Manual de horticultura orgânica. 2 ed. Viçosa, MG: Aprenda Fácil. 2006. 843 p.

SOUZA, C. R. de; LIMA, R. M. B. de; AZEVEDO, C. P. de; ROSSI, L. M. B. Sumaúma (Ceiba pentandra (L.) Gaerth). Manaus: Embrapa Amazônia ocidental, 2005. 22 p. (Documentos, 41).

SIMÕES, A. C.; ALVES, G. K. E. B.; FERREIRA, R. L. F.; ARAÚJO NETO, S. E. de. Qualidade da muda e produtividade de alface orgânica com condicionadores de substrato. Horticultura Brasileira, v.33, 4. P.518-523, 2015.

VIDIGAL, S. M.; PEDROSA, M. W. Couve-comum. In: PAULA JÚNIOR, T. J.; VENZON, M. 101 culturas: manual de tecnologias agrícolas. Belo Horizonte: EPAMIG, 2007. p. 295-298.

WATTHIER, M.; SILVA, M. A. S. da; SCHWENGBER, J. E.; FONSECA, F. D. da; NORMBERG, A. Produção de mudas e cultivo a campo de beterraba em sistema orgânico de produção. Revista Brasileira de Agropecuária Sustentável, v. 6, n. 2, p. 51-57, jun. 2016. 